\title{
Impact of Non-Pharmacological Intervention of Primary Osteoporosis in Elderly People at Suez Canal University Hospitals
}

\author{
Farida Kamel Yousef \\ Lecturer of Community Health Nursing Faculty of Nursing, Suez Canal University Egypt.
}

\begin{abstract}
Primary osteoporosis is simply the form seen in older persons and women postmenopausal in which bone loss is accelerated over that predicted for age and sex. The study aim is to evaluate the impact of the non-pharmacological intervention of primary osteoporosis in elderly people. Design: a quasi-experimental research study. Sampling \& setting: A purposive sample consisted of 30 elderly patients, both sexes were recruited from bone density measurement unit at Suez Canal University Hospital. Tools: Patient's assessment sheet, Body Mass Density by (Dual energy x-ray absorptiometry). A health education intervention was designed to improve osteoporotic patients' health condition and was evaluated two months after intervention. Results: There was a positive improvement regarding activities of daily living. Regarding sport, the mean of sporting time was $37.0 \pm 59.7$ changed to $59.3 \pm 53.2$ (post intervention), while exposure to the sun was $6.7 \%$ changed to $34.2 \%$ of post 2 months. Conclusion: Apply onpharmacological intervention by improving elderly practice exercise, take balanced diet contain calcium and prevent risk factors that lead to lack absorption of calcium, slightly enhance activities of daily living for study subjects Recommendation: Education about risk factors and preventative measures of osteoporosis need to start early in perimenopausal years and not be delayed to postmenopausal years.
\end{abstract}

Keywords: Primary Osteoporosis, Elderly, Non-Pharmacological Management \& Body Mass Index.

\section{Introduction}

Osteoporosis, a major public health problem, is becoming increasingly prevalent with the aging of the world population. Osteoporosis has become the fourth most common disease in aged adults. Due to the high degree of morbidity and mortality associated with fracture, prevention of such events is imperative because the number of women at risk for osteoporosis is expected to rise dramatically with the aging world population (Cauley, 2013).

Osteoporosis is a systematic disease in which bone density is reduced leading to the weakening of the skeleton and increase vulnerability to fractures (Wells et al., 2005). Osteoporosis can be classified as primary or secondary. Primary osteoporosis is simply the form seen in older persons and women postmenopausal in which bone loss is accelerated over that predicted for age and sex. Secondary osteoporosis results from a variety of unidentifiable (Sweet et al., 2009).

Primary osteoporosis occurs in patients, in whom a secondary cause of osteoporosis cannot be identified, including juvenile and idiopathic osteoporosis. Idiopathic osteoporosis can be further subdivided into postmenopausal (type I) and age-associated or senile (type II) osteoporosis. Juvenile osteoporosis usually occurs in children or young adults of both sexes Goltzman., 2008).

Some epidemiological data show that higher body weight of BMI, is positively correlated with bone mass, and weight loss may cause bone loss (Gunary, et al., 2003, Radak, 2004, \& Gundi, et al., 2007).

A frequent use of the BMI is to assess how much an individual's body weight departs from what is normal or desirable for a person of his or her height. The weight excess or deficiency may, in part, be accounted for by body fat (adipose tissue) although other factors such as muscularity also affect BMI significantly categories. Those categories are (1) severely underweight (MBI less than $16.5 \mathrm{~kg} / \mathrm{m}^{2}$, MBI prime less than 0.66), (2) underweight (MBI from 16.5 to $18.5 \mathrm{~kg} / \mathrm{m}^{2}$, MBI prime from 0.66 to 0.73 ), (3) normal (MBI from 18.5 to $24.9 \mathrm{~kg} / \mathrm{m}^{2}$, MBI prime from 0.74 to 0.99 ), (4) overweight (MBI from 25 to $29.9 \mathrm{~kg} / \mathrm{m}^{2}$, MBI prime from 1.00 to 1.19 ), (5) obese class I (MBI from 30 to $34.9 \mathrm{~kg} / \mathrm{m}^{2}$, MBI prime from 1.2 to 1.39 ), (6) obese class II (MBI from 35 to 39.9 $\mathrm{kg} / \mathrm{m}^{2}$, MBI prime from 1.4 to 1.59 ), (7) obese class III (MBI over $\mathrm{kg} / \mathrm{m}^{2}$, MBI prime over 1.6) (WHO, 2009).

Risk factors for osteoporosis fracture can be split between non-modifiable and (potentially) modifiable. In addition, there are specific diseases and disorders in which osteoporosis is a recognized complication. Medication use is theoretically modifiable, although in many cases the use of medication that increases osteoporosis risk is unavoidable (Lewiecki, 2011). The most important risk factors for osteoporosis are an advanced age of both sex, deficiency following menopause or ovary-ectomy is correlated with a rapid 
reduction in bone mineral density while in men a decrease in Testosterone levels has a comparable (but less pronounced) effect. While osteoporosis occurs in people from all ethnic groups, European or ancestry predisposes for osteoporosis (Body et al., 2011).

An inadequate supply of calcium over a lifetime contributes to the development of osteoporosis. Low calcium intake appears to be associated with low bone mass, rapid bone loss, and high fracture rates (Chan, et al., 2010). Deficiency of Vitamin D can result from; inadequate nutritional intake of vitamin D coupled with inadequate sunlight exposure, in particular, sunlight with adequate Ultra violet B rays, disorders that limit vitamin $\mathrm{D}$ absorption and conditions that impair the conversion of vitamin $\mathrm{D}$ into active metabolite including certain kidney, and hereditary disorders (Avenell, et al., 2009).

High caffeine intake has been associated with decreased bone mineral density in post-menopausal women who have low calcium intake (Wastta et al., 2012). The effect of smoking on fracture risk seems to be dose-dependent with an increasing risk with the years of smoking (Kanis et al., 2005).

Lack of physical activity is a risk factor for hip fractures and vertebral fractures. Immobility may be associated with and compounded by low or no exposure to sunlight and subsequent vitamin D deficiency (Korpelainen et al., 2006). Immobilization leads to rapid bone loss. The positive responses of the skeleton are site specific to the loading pattern and the type of activity also influences the degree of response of the bone loading (Englund et al., 2011).

Many diseases, conditions, and medications are associated with increased risk of osteoporosis and fractures. Fracture risk may be increased by diseases such as type 1 diabetes mellitus, primary hyperparathyroidism, hyper and hypothyroidism, rheumatoid arthritis, stroke, hypertension, inflammatory bowel disease, celiac disease, gastrectomy, asthma, chronic obstructive pulmonary disease, cystic fibrosis, renal disease, anorexia nervosa, pernicious anemia, Parkinson's, dementia and psychiatric disorders. Reasons for an association might be (e.g. inflammation, malabsorption, malnutrition, or a higher fall rate (Veatergaard et al., 2008).

Medications associated with increased fragility fracture risk include, but are not limited to corticosteroids, excessive thyroid hormone replacement, anti-androgen and anti-estrogen treatments (aromatase inhibitors), selective serotonin reuptake inhibitors, thiazolidinediones and certain anti-epileptic drugs. However, it is not always possible to distinguish the effect of the drug treatments from the effect of the underlying condition that required their use (Veatergaard, et al., 2009).

Nurses can be a vital part of the challenging solution to removing barriers and bridging the educational gap between bone health and osteoporosis throughout the lifespan, from children to elders. It provides many benefits for elderly by preventing future fractures and improving the quality of life in those afflicted with osteoporosis and low bone mass (Body, et al., 2011).

\section{Significance of the study}

The incidence of Osteoporosis in Egypt, data survey from the Egyptian National Nutrition Institute to determine bone mineral density (BMD) among the elderly in 2004 revealed that osteoporosis is a major health problem in Egypt. Also, about a third of the elderly population of both sexes (65 to over 80 years of age) was osteoporotic (Hassan et al., 2012). In addition to it has been more prevalent in females $2.2 \%$ than males $0.8 \%$ (Hassan, 2015).

Osteoporosis is one of the major causes of disability, morbidity and mortality in older people. It has an enormous impact on public health and on the quality of life of the elderly. In addition to the economic cost, minimal trauma fractures have devastating physical, psychological and social consequences. Pain, deformity, reduced mobility and increasing dependence all have an impact on activities of daily living and can have a profound impact on healthrelated quality of life (EL-Hajj Fuleihan et al., 2011).

Educational strategies are essential for patients with osteoporosis for several reasons. Osteoporosis is clinically silent until fractures occur while changes in fracture risk don't necessarily make patients 'feel' different physically. Provision of health education can allay anxiety and fear of the future, providing knowledge about the condition, and confidence in making good choices about health-related behaviors. In this way, education also maintains patient interest and helps improve patient outcomes concerned with preventive measures (Mac Laughlin \& Raehl, 2008).

\section{Aim of the study}

The aim of this study is to evaluate the impact of non-pharmacological intervention of primary osteoporosis in elderly people at Suez Canal University Hospitals through:

- Assessing of Body Mass Index, functional status by Activity of Daily Living and Instrumental Activity of Daily Living, and body mass density by DEXA (Dual energy x-ray absorptiometry). 
- Designing and implementing health education intervention using of non-pharmacological management

- Evaluating the of impact the designed health education intervention on condition of patients with osteoporosis

\section{Research question}

What is the impact of using non-pharmacological intervention on condition of patients with osteoporosis?

\section{Methodology}

Study design: the present study is a quasiexperimental rear arch study, which has been designed aiming to study the impact of using nonpharmacological intervention on condition of patients with osteoporosis

\section{Setting}

The study was conducted in bone density measurement unit at Suez Canal University Hospital.

\section{Description of the setting:}

A single room inside the X-ray department, it provides inpatient, outpatient, and health insurance services. This unit includes DEXA (Dual Energy Xray Absorptiometry) which connected with a computer connected to the printer. A DEXA scan is a quick and painless procedure that involves patient lying on back on a padded X-ray table so that an area of the body can be scanned. On the day of the examination, the patient should not take calcium supplements for at least 24 hours before the exam.

\section{Sampling and sample size}

A purposive sample consisted of 30 elderly patients (60 years old and above), both sexes, have a primary type of osteoporosis, and was newly diagnosed to be osteoporotic by DEXA. Persons were considered to be osteoporotic if T-score $\leq-2.5$ (WHO, 2009). Not enrolled in any previous program course and agreed to participate in the study, fulfilled these criteria in the above-mentioned settings.

\section{Exclusion criteria:}

Patients having the secondary type of osteoporosis (arthritis, liver disease, thyroid problem, etc.), and using medication as (corticosteroids, anticoagulants drugs).

Tools of data collection

A structured interview questionnaire covered:

1. Demographic characteristics: (age, sex, level of education, marital status, and occupation).

2. Anthropometric measurement: which converts body mass index (BMI); height and weight are obtained for each elderly to calculate body mass index (BMI) as an indicator of the degree of malnutrition using the following equation according to (Castillo-Martinez, et al., 2012).
Body Mass Index $($ BMI $)=($ Weight $/ \mathrm{kg}) /($ Height in meter) ${ }^{2}$

- Underweight $<18$

- standard level BMI $\geq 18-24.9$

- Overweight $\geq 25$ - 29.9

- Obese $\geq 30-40$

- Morbid obese > 40

3. Assessing personal habits (smoking, drinking) and dietary habits (amount of milk consumption, fruits, vegetables, legumes, and peanuts), as well as food items that have negative effect on calcium absorption and bone health such as(tea, coffee, soda drinks, Nescafe, salt in food, pickles active or passive smoking). The scoring system was as the follows, the item reported done were scored (1) (yes), and not done were scored (zero) (No). The frequencies of dietary calcium intake/week were calculated by simple summation and classified as

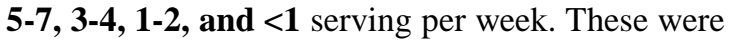
summed and scored as imbalanced and balanced; (7-17) and (18-28) respectively. Similarly, the risky dietary habits were calculated by simple summation and classified into maximum and median per day. These were summed and scored as low-risk diet and high-risk diet; (1-6) and (7-12) respectively, and giving a mean score for the part. These scores were converted into a percent score, mean, SD.

4. Assessment of functional status by Activity of Daily Living. (Ability to perform activities of daily living (ADLs) as "bathing, dressing, toileting, transferring, continence, and feeding". In ADLs each function is scored at three-point scale (independent $=2$, partially dependent $=1$, and dependent $=$ zero). Summation of items scores yields a total score ranging from "zero to 12 ". Where score $0-5=$ completely dependent, $6-9=$ partially dependent, and 10-12 = independent.

5. Assessment of Body Mineral Density (BMD) by DEXA (Dual energy $x$-ray absorptiometry). It is the most widely used technique for measuring bone density. In the present study, BMD measured at the femoral neck, the lumber spine, and in the dominant forearm. Bone density measurements were obtained from elders' records. The results are usually reported as "T" and "Z" score. The "Tscore" compares the bone density of study sample with that the young normal reference means (thirtyyear-old). The " $Z$ " score compares the bone density of study sample with that of other people of the same age and gender. The score below -2.5 indicates osteoporosis. The more negative score, the thinner the bones (National Osteoporosis Foundation, 2008).

6. Intervention session: It is modified in the Arabic language to give knowledge about osteoporosis 
disease; risk factors for osteoporosis, causes, signs and symptoms, complications. Diet for patients with osteoporosis, exercise program, and safety measures to prevent falling and fractures. A review of current, past, local and international related literature and theoretical knowledge of various aspects of the study using books, articles, the internet, periodicals, and magazines was done.

\section{Pilot study}

It was carried out on 3 osteoporotic patients fulfilling the selected criteria and excluded from the study. They were selected randomly when attended to bone density measurement unit at Suez Canal University hospital for testing clarity, arrangement, and content applicability of items, also to determine the time required to conduct the constructed tools of the research. Items were rearranged and modification of the tools was done based on the findings of the pilot study. Some questions and items were omitted, added, or rephrased, and then the final form was developed. The subjects included in the pilot study were excluded from the study subjects.

\section{Procedure}

- The data collection was done first using the interview questionnaire sheet, after identifying the elderly who fulfilled the criteria of the study, the researcher explained the aim of the study to the elderly, and their consent to participate was obtained orally, the activity took place in the previously mentioned setting in the waiting area. The questionnaire sheets were filled by the researcher by asking the elderly. The average time spent with each participant to be interviewed 25-35 minutes.

- The intervention was set in five sessions covering the definitions and risk factors of osteoporosis; symptoms of osteoporosis and its complications; prevention of osteoporosis; factor prevent absorption of calcium; an example of preventive nutrition; and exercise to prevent osteoporosis and precautions to prevent fractures. Posters and handouts about the care were used. Each session lasted for 30-35 minutes and was accompanied by many feedbacks and also, finishing the session by reminding about the time of follow-up. The total duration of this phase of the study was 8-10 weeks. The researcher encouraged the participants to bring their relatives with them to know how to support and help them in their care, and the follow-up sessions after 2 months from the last session to evaluate the effect of the intervention on the physiological condition of patients.

- Permission to collect data and implement of the educational intervention in the bone density measurement unit at Suez Canal University hospital was obtained from hospital administration.
This was through submission of a formal letter from the dean of the Faculty of Nursing Suez Canal University. Meetings and discussions were held between the researcher and the participants to make them aware about the objective of educational intervention.

\section{Ethical considerations}

An oral agreement for the participation of the subjects was taken from the participants. After explaining the aim of the study to them, they were given an opportunity to refuse or to withdraw at any phase if they want without any reasons and they were assured that the information that was taken from them would be confidential and used for the research purpose only.

\section{Statistical analysis}

After collection of the data they were revised, coded and fed to statistical software SPSS version 18. The given graphs were constructed using Microsoft excel software. 


\section{Results}

Table (1): Distribution of the studied subjects according to their demographic characteristics $(\mathrm{No}=30)$.

\begin{tabular}{|c|c|c|c|}
\hline \multicolumn{2}{|r|}{ Items } & No & $\%$ \\
\hline \multirow{3}{*}{ Age groups/years } & $60-69$ & 19 & 63.3 \\
\hline & $70-79$ & 8 & 26.7 \\
\hline & $80>$ & 3 & 10.0 \\
\hline \multicolumn{2}{|r|}{ Mean \pm SD } & \multicolumn{2}{|c|}{$68.4 \pm 6.8$ years } \\
\hline \multirow{2}{*}{ Gender } & Female & 26 & 86.7 \\
\hline & Male & 4 & 13.3 \\
\hline \multirow{2}{*}{ Marital status } & Single (divorced/widow) & 13 & 43.3 \\
\hline & Married & 17 & 56.7 \\
\hline \multirow{4}{*}{$\begin{array}{l}\text { Level of } \\
\text { education }\end{array}$} & Illiterate & 15 & 50.0 \\
\hline & read and write & 7 & 23.3 \\
\hline & Basic & 5 & 16.7 \\
\hline & Middle (secondary) & 3 & 10.0 \\
\hline \multirow{3}{*}{ Occupation } & Housewife & 14 & 46.7 \\
\hline & Skilled & 3 & 10.0 \\
\hline & unskilled & 13 & 43.4 \\
\hline
\end{tabular}

Table (2): Distribution of the studied subjects by smoking history.

\begin{tabular}{|c|c|c|c|}
\hline \multicolumn{2}{|r|}{ Items } & No & $\%$ \\
\hline \multirow{3}{*}{ smoking } & - $\quad \mathrm{No}$ & 16 & 33.3 \\
\hline & - Active & 7 & 23.3 \\
\hline & - $\quad$ Passive & 7 & 23.3 \\
\hline \multicolumn{2}{|c|}{ Smoking index (active) Min-max } & \multicolumn{2}{|c|}{$3.0-900.0$} \\
\hline \multicolumn{2}{|r|}{ Mean \pm SD } & \multicolumn{2}{|c|}{$336.3 \pm 326.5$} \\
\hline \multicolumn{2}{|c|}{ Smoking index (passive) } & \multicolumn{2}{|c|}{$20.0-1000.0$} \\
\hline & Mean \pm SD & \multicolumn{2}{|c|}{$424.3 \pm 356.6$} \\
\hline \multicolumn{2}{|c|}{ Stopped smoking } & 5 & 16.7 \\
\hline \multicolumn{2}{|c|}{ Stopped smoking since (year) Min-max } & \multicolumn{2}{|c|}{$5.0-20.0$} \\
\hline & Mean \pm SD & \multicolumn{2}{|c|}{$12.2 \pm 5.8$} \\
\hline
\end{tabular}

Table (3): Distribution of the studied subjects by their anthropometric measures.

\begin{tabular}{|c|c|c|c|}
\hline & Weight & Height & $\begin{array}{c}\text { BMI } \\
\text { Body Mass Index }\end{array}$ \\
\hline Mean & 65.26 & 152.54 & 27.09 \\
\hline $\mathbf{\text { SD }}$ & 13.37 & 21.12 & 6.11 \\
\hline
\end{tabular}

Table (4): Distribution of the studied subjects by Body Mass Index (BMI) and their gender.

\begin{tabular}{|c|c|c|}
\hline \multirow{2}{*}{} & \multicolumn{2}{|c|}{ BMI } \\
\cline { 2 - 3 } & Mean & $\mathbf{\pm S D}$ \\
\hline Male & 25.00 & 5.24 \\
\hline Female & 27.38 & 6.22 \\
\hline
\end{tabular}


Table (5): Distribution of the studied subjects according to their anthropometric measures and Body Mass Index (BMI).

\begin{tabular}{|c|c|c|c|c|c|c|}
\hline & \multicolumn{2}{|c|}{ Weight } & \multicolumn{2}{|c|}{ Height } & \multicolumn{2}{|c|}{$\begin{array}{c}\text { BMI } \\
\text { Body Mass Index }\end{array}$} \\
\hline & $\mathbf{R}$ & P (Sig) & $\overline{\mathbf{R}}$ & P (Sig) & $\mathbf{R}$ & P (Sig) \\
\hline T-LS BMD & 0.229 & $0.035(\mathrm{~S})$ & 0.222 & $\begin{array}{l}122 \\
(\mathrm{~S})\end{array}$ & 0.208 & $\begin{array}{l}0.147 \\
(\mathrm{NS})\end{array}$ \\
\hline T-FN BMD & 0.351 & $013(\mathrm{~S})$ & 0.096 & $\begin{array}{l}507 \\
(\mathrm{~S})\end{array}$ & 0.359 & $\begin{array}{l}011 \\
(\mathrm{~S})\end{array}$ \\
\hline
\end{tabular}

$P>0.05=$ Not Significant

$P<0.05=$ Significant

Table (6): Distribution of the studied subjects according to their correct knowledge score about osteoporosis (pre-post intervention).

\begin{tabular}{|c|c|c|c|c|c|c|}
\hline \multirow{3}{*}{ Knowledge items } & \multicolumn{4}{|c|}{ Phase of intervention } & \multirow{3}{*}{$\mathbf{T}$} & \multirow{3}{*}{$\mathbf{P}$} \\
\hline & \multicolumn{2}{|c|}{ Pre-intervention } & \multicolumn{2}{|c|}{ Post intervention } & & \\
\hline & Mean & SD & Mean & SD & & \\
\hline Definition of osteoporosis & 1.04 & 1.64 & 3.00 & 0.00 & -10.4 & $0.000 *$ \\
\hline Factors increases osteoporosis & 1.88 & 1.22 & 8.91 & 0.29 & 46.6 & $0.000 *$ \\
\hline $\begin{array}{l}\text { Common site of fracture due to } \\
\text { osteoporosis }\end{array}$ & 0.75 & 0.44 & 3.5 & 1.4 & -23.3 & $0.000 *$ \\
\hline Symptoms of osteoporosis & 1.04 & 0.65 & 4.99 & 0.12 & 47.8 & $0.000 *$ \\
\hline Prevention of osteoporosis & 2.08 & 1.11 & 8.00 & 0.00 & -46.0 & $0.000 *$ \\
\hline Types of exercises to prevent osteoporosis & 0.84 & 0.90 & 9.99 & 0.12 & 83.0 & $0.000 *$ \\
\hline Bone components & 0.95 & 1.63 & 3.00 & 0.00 & -10.9 & $0.000 *$ \\
\hline Ca. sources & 1.21 & 0.68 & 4.00 & 0.00 & -35.3 & $0.000 *$ \\
\hline Factors prevent Ca. absorption & 0.71 & 0.65 & 5.00 & 0.00 & 56.9 & $0.000 *$ \\
\hline Vit. D. affects bone composition & 0.58 & 0.22 & 1.00 & 0.00 & 1.7 & 0.201 \\
\hline Vit. D. sources & 1.12 & 0.87 & 5.00 & 0.00 & -38.7 & $0.000 *$ \\
\hline Precautions to prevent fractures & 1.92 & 1.15 & 9.00 & 0.00 & 53.4 & $0.000 *$ \\
\hline Total mean score of knowledge & 15.73 & 5.79 & 64.87 & 0.34 & -72.8 & $0.000 *$ \\
\hline
\end{tabular}

T: Paired t-test for related samples

$* P<0.05$ (significant)

Table (7): Distribution of the studied subjects according to their Dual energy x-ray absorptiometry (DEXA) scores (pre/post intervention).

\begin{tabular}{|c|c|c|c|c|c|c|}
\hline \multirow{2}{*}{ Sites/ DEXA scores } & \multicolumn{2}{|c|}{ pre intervention } & \multicolumn{2}{|c|}{ post intervention } & \multirow{2}{*}{$\begin{array}{c}\mathrm{X}^{2} \\
\text { test }\end{array}$} & \multirow{2}{*}{$P$ value } \\
\hline & No. & $\%$ & No. & $\%$ & & \\
\hline \multicolumn{7}{|l|}{ Forearm } \\
\hline Normal (T >-1.0 SD) & 2 & 6.7 & 2 & 6.7 & \multirow{3}{*}{1.49} & \multirow{3}{*}{0.83} \\
\hline Osteopenia (T -1.0 to $2.5 \mathrm{SD}$ ) & 13 & 43.3 & 13 & 43.3 & & \\
\hline Osteoporosis ( $\mathrm{T}<2.2 .0 \mathrm{SD})$ & 15 & 50.0 & 15 & 50.0 & & \\
\hline \multicolumn{7}{|l|}{ Femur } \\
\hline Normal (T >-1.0 SD) & 8 & 26.7 & 9 & 30.0 & \multirow{3}{*}{1.28} & \multirow{3}{*}{0.86} \\
\hline Osteopenia (T -1.0 to $2.5 \mathrm{SD}$ ) & 14 & 46.7 & 15 & 50.0 & & \\
\hline Osteoporosis ( $\mathrm{T}<2.2 .0 \mathrm{SD})$ & 8 & 26.7 & 6 & 20.0 & & \\
\hline \multicolumn{7}{|l|}{ Spine } \\
\hline Normal ( $\mathrm{T}>-1.0 \mathrm{SD})$ & 3 & 10.0 & 3 & 10.0 & \multirow{3}{*}{0.84} & \multirow{3}{*}{0.93} \\
\hline Osteopenia (T -1.0 to $2.5 \mathrm{SD}$ ) & 3 & 10.0 & 3 & 10.0 & & \\
\hline Osteoporosis ( $\mathrm{T}<2.2 .0 \mathrm{SD})$ & 24 & 80.0 & 24 & 80.0 & & \\
\hline
\end{tabular}

$* P<0.05$ (significant) 
Table (8): Distribution of the studied subjects according to their dietary habits and lifestyle changes throughout the (pre/post intervention).

\begin{tabular}{|c|c|c|c|c|c|c|}
\hline \multirow{2}{*}{$\begin{array}{c}\text { lifestyle and dietary habits } \\
\text { changes }\end{array}$} & \multicolumn{2}{|c|}{ Pre-intervention } & \multicolumn{2}{|c|}{ post-intervention } & \multirow{2}{*}{$\mathrm{X}^{2}$ test } & \multirow{2}{*}{$P$ value } \\
\hline & No. & $\%$ & No. & $\%$ & & \\
\hline Prolonged sitting & 20 & 66.7 & 14 & 46.7 & 3.21 & 0.20 \\
\hline Prolonged standing & 14 & 46.7 & 10 & 33.3 & 1.51 & 0.47 \\
\hline sporting & 5 & 16.7 & 7 & 23.3 & 1.06 & 0.59 \\
\hline Sporting time (mean \pm SD) & \multicolumn{2}{|c|}{$37.0 \pm 59.7$} & \multicolumn{2}{|c|}{$59.3 \pm 53.2$} & 1.92 & 0.31 \\
\hline Exposure to sun & 2 & 6.7 & 13 & 60.0 & 30.15 & $<0.001 * *$ \\
\hline Smoking index (mean \pm SD) & \multicolumn{2}{|c|}{$380.3 \pm 331.6$} & \multicolumn{2}{|c|}{$380.3 \pm 331.6$} & 0.03 & 0.96 \\
\hline Quit smoking & 5 & 16.7 & 7 & 23.3 & 0.53 & 0.77 \\
\hline $\begin{array}{l}\text { Adequate dietary calcium } \\
(1200 \mathrm{mg} / \text { day })\end{array}$ & 4 & 13.3 & 16 & 53.3 & 17.10 & $<0.001 * *$ \\
\hline Adding salt & 18 & 60.0 & 1 & 3.3 & 40.96 & $0.001 * *$ \\
\hline $\begin{array}{l}\text { Total animal protein } \\
\text { servings/week }(\text { mean } \pm \text { SD) }\end{array}$ & \multicolumn{2}{|c|}{$2.8 \pm 1.4$} & \multicolumn{2}{|c|}{$5.2 \pm 0.9 \pm$} & 50.92 & $<0.001 * *$ \\
\hline $\begin{array}{l}\text { Total caffeinated drinks } \\
\text { (time/day) }\end{array}$ & \multicolumn{2}{|c|}{$3.0 \pm 2.1$} & \multicolumn{2}{|c|}{$2.0 \pm 1.0$} & 5.11 & $0.008^{*}$ \\
\hline
\end{tabular}

*Statistical significant

**Highly Statistical significant

Table (9): Distribution of the studied subjects according to their activities of daily living and risk exposure throughout (pre/post intervention).

\begin{tabular}{|l|c|c|c|c|c|c|}
\hline \multirow{2}{*}{\multicolumn{1}{|c|}{ Daily living activities }} & \multicolumn{2}{c|}{ Pre intervention } & \multicolumn{2}{c|}{ post intervention } & \multirow{2}{*}{$\mathbf{X}^{\mathbf{2}}$ test } & $\begin{array}{c}\text { P } \\
\text { value }\end{array}$ \\
\cline { 2 - 7 } & $\mathbf{N o}$ & $\mathbf{\%}$ & $\mathbf{N o}$ & $\mathbf{\%}$ & & -- \\
\hline Able to shower & 28 & 93.3 & 29 & 96.7 & -- & -- \\
\hline Able to cloth & 28 & 93.3 & 29 & 96.7 & -- & -- \\
\hline Able to move around & 20 & 66.7 & 19 & 63.3 & 0.10 & 0.95 \\
\hline Able to domestic work & 12 & 40.0 & 11 & 36.7 & 0.09 & 0.95 \\
\hline Overall activities & 10 & 33.3 & 9 & 30.0 & 010 & 0.95 \\
\hline $\begin{array}{l}\text { Exposed to risk in } \\
\text { bathroom }\end{array}$ & 15 & 50.0 & 15 & 50.0 & 0.00 & 1.00 \\
\hline Exposed to risk at home & 6 & 20.0 & 6 & 20.0 & 0.00 & 1.00 \\
\hline Exposed to risk in street & 5 & 16.7 & 5 & 16.7 & -- & -- \\
\hline
\end{tabular}

Table (10): Distribution of the studied subjects according to their knowledge about osteoporosis throughout (pre/post intervention).

\begin{tabular}{|l|c|c|c|c|c|c|}
\hline \multirow{2}{*}{ Items } & \multicolumn{2}{|c|}{ Pre intervention } & \multicolumn{2}{c|}{ post intervention } & \multirow{2}{*}{ X $^{2}$ test } & \multirow{2}{*}{ P value } \\
\cline { 2 - 6 } & No. & $\%$ & No. & $\%$ & \\
\hline osteoporosis & 10 & 33.3 & 22 & 73.3 & 20.17 & $<0.001^{* *}$ \\
\hline definition & 2 & 6.7 & 17 & 56.7 & 33.76 & $<0.001^{* *}$ \\
\hline Causes & 0 & 0.0 & 18 & 60.0 & 44.44 & $<0.001^{* *}$ \\
\hline Symptoms/signs & 0 & 0.0 & 17 & 56.7 & 43.66 & $<0.001^{* *}$ \\
\hline Diagnosis & 2 & 6.7 & 25 & 83.3 & 90.0 & $<0.001^{* *}$ \\
\hline Treatment & 0 & 0.0 & 22 & 73.7 & 45.07 & $<0.001^{* *}$ \\
\hline Precautions & 4 & 13.3 & 20 & 66.7 & 34.92 & $<0.001^{* *}$ \\
\hline complications & 1 & 3.3 & 21 & 70.0 & 56.47 & $<0.001^{* *}$ \\
\hline Prevention & 0 & 0.0 & 12 & 46.2 & 41.15 & $<0.001^{* *}$ \\
\hline Side-effects of hormones & & & & & \\
\hline
\end{tabular}




\begin{tabular}{|c|c|c|c|c|c|c|}
\hline \multirow{2}{*}{ Items } & \multicolumn{2}{|c|}{ Pre intervention } & \multicolumn{2}{|c|}{ post intervention } & \multirow{2}{*}{$\mathrm{X}^{2}$ test } & \multirow{2}{*}{$P$ value } \\
\hline & No. & $\%$ & No. & $\%$ & & \\
\hline \multicolumn{7}{|l|}{ Effects of } \\
\hline Smoking & 3 & 10.0 & 9 & 30.0 & 5.17 & 0.08 \\
\hline Diet & 11 & 36.7 & 30 & 100.0 & 48.17 & $<0.001 * *$ \\
\hline Caffeinated drinks & 0 & 0.0 & 13 & 43.3 & 29.57 & $<0.001 * *$ \\
\hline Exercise & 6 & 20.0 & 25 & 83.3 & 34.13 & $<0.001 * *$ \\
\hline Exposure to sun & 6 & 20.0 & 20 & 66.7 & 22.13 & $<0.001 * *$ \\
\hline \multicolumn{7}{|l|}{ Prevention of risk at } \\
\hline Bathroom & 8 & 26.7 & 25 & 83.3 & 30.21 & $<0.001 * *$ \\
\hline Home & 1 & 3.3 & 17 & 56.7 & 28.51 & $<0.001 * *$ \\
\hline Street & 1 & 3.3 & 22 & 73.3 & 43.37 & $<0.001 * *$ \\
\hline \multicolumn{7}{|l|}{ Total knowledge about } \\
\hline Osteoporosis & 0 & 0.0 & 20 & 66.7 & 52.46 & $<0.001 * *$ \\
\hline Effects of risk factors & 0 & 0.0 & 17 & 56.7 & 28.71 & $<0.001 * *$ \\
\hline Prevention of risks & 2 & 6.7 & 23 & 76.7 & 43.83 & $<0.001 * *$ \\
\hline Total & 0 & 0.0 & 19 & 63.3 & 40.45 & $<0.001 * *$ \\
\hline
\end{tabular}

**Highly Statistical significant

Table (11): Comparison between categories of Body Mass Index (BMI) as regard Body Mineral Density (BMD) among all participants.

\begin{tabular}{|c|c|c|c|c|c|c|c|c|}
\hline & \multicolumn{6}{|c|}{ BMI } & \multirow{3}{*}{$\begin{array}{c}\begin{array}{c}\text { ANOVA } \\
\text { test }\end{array} \\
\text { P (Sig) }\end{array}$} & \multirow{3}{*}{ Post hoc test } \\
\hline & \multicolumn{2}{|c|}{$\begin{array}{c}<25 \\
(\text { Gr1 }) \\
\end{array}$} & \multicolumn{2}{|c|}{$\begin{array}{c}25-29.9 \\
\text { (Gr2) }\end{array}$} & \multicolumn{2}{|c|}{$\begin{array}{l}>=30 \\
(G r 3)\end{array}$} & & \\
\hline & Mean & $\pm \mathrm{SD}$ & $\pm \mathrm{SD}$ & \pm SD & $\pm \mathrm{SD}$ & $\pm \mathrm{SD}$ & & \\
\hline $\begin{array}{l}\text { T-LS } \\
\text { BMD }\end{array}$ & -2.98 & 1.14 & -2.02 & 1.71 & -1.44 & 1.46 & $\begin{array}{l}0.001 \\
\text { (HS) }\end{array}$ & $\begin{array}{l}\text { Gr1Vs Gr2 } \\
\text { Gr1Vs Gr3 }\end{array}$ \\
\hline $\begin{array}{l}\text { T-FN } \\
\text { BMD }\end{array}$ & -2.24 & 1.20 & -1.58 & 1.38 & -1.10 & 1.13 & $\begin{array}{l}0.001 \\
(\mathrm{HS})\end{array}$ & Gr1Vs Gr3 \\
\hline
\end{tabular}

$P<0.01=$ Highly Significant

Table (1): Distribution of the studied subjects according to their demographic characteristics $(\mathrm{No}=30)$

It showed that socio- demographic characteristics of the study group, it revealed that $86.7 \%$ are female, and the mean age of elderly was $68.4 \pm 6.8$ years. As regards their educational level $50.0 \%$ were illiterate and $23.3 \%$ just read and write, while $10.0 \%$ had a middle education. Also, the results found that $46.7 \%$ were a housewife. Meanwhile, $56.7 \%$ of the study subjects were married.

Table (2): Distribution of the studied subjects by smoking history

This table illustrated that the mean smoking index (active) was $336.3 \pm 326.5$ of the study group. The

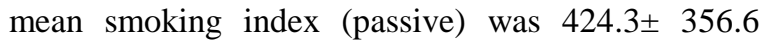
while the mean stopped smoking since the year was $12.2 \pm 5.8$.

Table (3): Distribution of the studied subjects by their anthropometric measures
This table revealed that the mean of Body Mass Index (BMI) of elderly was 27.09 \pm 6.11 .

Table (4): Distribution of the studied subjects by Body Mass Index (BMI) and their gender

Table 4, illustrates, the body mass index of the studied subjects in different sex, the mean BMI of female subjects was $27.38 \pm 6.22$ while mean BMI of male subjects was $25.00 \pm 5.24$.

Table (5): Distribution of the studied subjects according to their anthropometric measures and Body Mass Index (BMI)

This table shows statistical significance between weight, and height with T-LS BMD and T-FN BMD, while, statistically no significance between BMI with T-LS BMD among all participants.

Table (6): Distribution of the studied subjects according to their correct knowledge score about osteoporosis (pre-post intervention)

Table (6) indicates the studied subjects correct knowledge pre-post intervention phase about 
osteoporosis. The result revealed a significant statistical difference in total mean score of knowledge about osteoporosis pre-post intervention $(\mathrm{P}=0.000)$. The highest mean score of correct knowledge post intervention for their knowledge about types of exercise leads to prevent osteoporosis $(9.99 \pm 0.12)$ compared to $0.84 \pm 0.90$ preintervention. While a low mean score of knowledge pre-intervention for the factors prevent $\mathrm{Ca}$ absorption $0.71 \pm 0.65$ compared to $5.00 \pm 0.00$ post- intervention. These differences between pre-post intervention phase were highly statistically significant $(\mathrm{P}=0.000)$.

Table (7): Distribution of the studied subjects according to their Dual energy x-ray absorptiometry (DEXA) scores

This table shows that $50 \%$ of study group have osteoporosis of both forearm and femur. Also, 73.3\% have spine osteoporosis before the intervention. There was no statistically significant difference subjects study pre \&post intervention regarding DEXA finding of the forearm, femur, and spine.

Table (8): Distribution of the studied subjects according to their dietary habits and lifestyle changes throughout (pre-post intervention)

There was a positive improvement regarding lifestyle relevant the following areas post 2 months of intervention. Regarding prolonged sitting, it was $66.7 \%$ pre-intervention changed to $46.7 \%$ post intervention, while prolonged standing was 46.7 changed to $33.3 \%$ post intervention. Regarding sport, the mean of sporting time was $37.0 \pm 59.7$ changed to $59.3 \pm 53.2$ (post intervention), while exposure to the sun was $6.7 \%$ changed to $34.2 \%$ of post 2 months. Quitting smoking was $16.7 \%$ changed to $23.3 \%$ post intervention.

Regarding dietary habits changes relevant to adequate dietary calcium, adding salt, mean of total animal protein and total caffeinated drinks, there was a highly statistically significant difference among the intervention phases in the study group.

Table (9): Distribution of the studied subjects according to their activities of daily living and risk exposure throughout (pre-post intervention)

There was a positive improvement regarding activities of daily living relevant to the ability to shower and cloth was $93.3 \%$ pre-changed to $96.7 \%$ post intervention. Regarding the rest of activities of daily living in the table and risk exposures, there was no statistically significant difference among the intervention phases.

Table (10): Distribution of the studied subjects according to their knowledge about osteoporosis throughout the (pre-post intervention)

This table showed that there was highly statistically significant difference throughout the intervention among the subjects study regarding total knowledge about osteoporosis, the effect of risk factors and prevention of risks.

Table (11): Comparison between categories of body Mass Index (BMI) as regard Body Mineral Density (BMD) among all participants

This table shows statistically high significant difference between Gr1 and Gr2 as regard T-LS BMD higher in Gr2 than Gr1, and statistically high significant difference between gr1 and Gr3 as regard T-LS BMD and T-FN BMD being higher in Gr3 than in Gr1among all participants

\section{Discussion}

Osteoporosis is a disorder in which lose of bone strength leads to fragility fractures. The fundamental pathogenesis mechanisms underlying this disorder, which include; failure to achieve a skeleton of optimal strength during growth and development, excessive bone resorption resulting in loss of bone mass and disruption of architecture, and failure to replace lost bone due to defects in bone formation (Prentice et al., 2012). The present study was conducted to evaluate the impact of nonpharmacological intervention among elderly people with primary osteoporosis.

The majority of the studied subjects were women; it may reflect a higher prevalence of osteoporosis among women. It also reflects the higher life expectancy of women in general, and in Egypt as shown in the Central Intelligence Agency report where the life expectancy was 70.8years for male and 76.2 years for female people (CIA, 2014). This finding supported by World Health Organization report (WHO) (2014), reported, women suffer more from hip fractures; their lifetime risk for osteoporotic fractures is at least $30 \%$. In contrast, fracture risk is only $13 \%$ in men. This might be attributed to estrogen deficiency is play a critical role in the development of osteoporosis.

Similarly, Waugh et al., (2009), in the USA found that the elderly women are at greater risk of osteoporosis as they have smaller bones and hence lower total bone mass. This might be due to hormonal changes that occur in the menopause directly affect bone density by decreasing the efficiency of intestinal calcium absorption and enhancing the ability of osteoclasts to resorb bones (Hernlund et al., 2013), Here are the main reasons; women have less bone mass at adulthood than men do. The male hormone testosterone protect men's bones as they age in their $60 \mathrm{~s}$ and 70s, women on another hand, need the hormone replacement after menopause, estrogen level fall.

The mean age was about $68.4 \pm 6.8$ years. Greco et al., (2010), found results in a cross-sectional study on 
3803 women aged 50-75 where they conclude that the numbers of years postmenopausal were the strongest inverse predictor of bone density. Lewiecki (2011) recorded that aging above 70 years had a risk factor for osteoporosis. This explained by aging reduces the ability of the intestine to adapt to a lowcalcium diet and maintain adequate calcium absorption. Additionally, absorption and formation of vitamin $\mathrm{D}$ in skin reduce with aging.

As regarding educational level, the majority of the studied subjects was illiterate or just read and writes. In the study conducted by Rariden (2012), the study showed that lower educational attainment will be associated with higher levels of osteoporosis among individuals age 65 and older. This could be associated with decreased health literacy levels in individuals age 65 and older.

Concerning, the marital status is another important factor that may affect osteoporosis. Thus, half of the studied subjects were single (divorced and widowed). Living alone may discourage the elderly person in the following healthy dietary habits. A similar finding was reported by Feldblum et al., (2011) in Ireland who clarified that eating alone can be difficult for older people who have reached a stage in life where many of their loved ones have either died or moved away. For many, a loss of appetite follows the loss of companionship. An Older person who has lost their wives (who did the cooking) may be at special risk. In addition to when they are at home, often they don't eat because they are depressed, lonely, sick, or incapable of fixing much.

Moreover, in the developing countries, the prevalence of osteoporosis increased among the aging population especially females. However, with low socioeconomic status, the high rate of illiteracy, with the rising cost of diagnosis and excessive focusing on curative rather than preventive service. All of these factors make it especially difficult for the developing countries to develop effective strategies for dealing with the rapid increase of a non-communicable disease as osteoporosis.

The current study revealed that less than half of the study subjects were obese, increase elderly weight due to increase age, bad nutritional habits and lack of activities in addition to hormonal changes associated with old age all these factors lead to a decrease in bone density. In contrast with Kim et al., (2010), who conducted across-sectional study on 907 postmenopausal healthy female subjects, age 60-79 years, were recruited from women hospitals in Seoul, South Korea, to evaluate the associations between obesity and bone mineral density (BMD) and body composition including body weight, percentage body fat, and waist circumference were measured. They found that after adjusting for age, smoking status, alcohol consumption, total calcium intake, and total energy intake, body weight was positively related to BMD of all sites. The explanation of the increase body weight of the patients in the recurrent study that could be due to increase age decrease the body activities and in addition to hormonal changes associated with old age bad nutritional habits, which lead to a negative effect on bone density among the subjects study.

This study showed that highly statistical significant throughout the intervention phases regarding knowledge about osteoporosis related to the main items of osteoporosis (definition, causes, risk factors, prevention of risks, and prevention of osteoporosis) among study subjects. These results are in

agreement with Ayoub et al., (2007) whose study in Egypt showed a positive effect of a comprehensive education program on knowledge about osteoporosis. On the same line, Rizzoli et al., (2010) whose study in Switzerland, found that health education and behavioral change programs can help elderly to modify their lifestyle in order to improve their bone health. Increased awareness of the consequences of low calcium and vitamin D intakes and increased awareness of dietary sources of calcium and vitamin D may improve elderly's attitudes towards dietary sources, in particular, dairy products, and lead to better adherence to health recommendations.

Regarding dietary habits changes relevant to adequate dietary calcium, adding salt, mean of total animal protein and total caffeinated drinks, there was a highly statistically significant difference among the intervention phases in the study group. Diets high in animal protein, sodium, or caffeine may also interfere with calcium absorption. Lewiecki, (2011), reported that the adequate calcium intake through milk and milk products in childhood and adolescence is a decisive marker for bone and for prevention of osteoporosis. The recommended dietary allowance of calcium has been fixed to $1200 \mathrm{mg} /$ day. Inadequate vitamin $\mathrm{D}$ less calcium is absorbed in the intestines of people with inadequate vitamin D levels. Moreover, phytic acid and oxalic acid, found naturally in some plants, foods with high levels of oxalic acid include spinach, collard greens, sweet potatoes, rhubarb, and beans, the extent to which these compounds affect calcium absorption Fenton et al., (2008), The female teenager is in a need of calcium in order for the bone structure to complete. The female teenager is in a bad need of this element at this age to avoid osteoporosis at postmenopausal age. The female teenager should also reduce desserts and the drinks that contain soda because this will lead to losing appetite and increasing the risk of obesity at older ages.

Caffeine induces a negative calcium balance through increased urinary loss. Additionally, a study in 
Australia by Berecki-Gisolf et al., (2010), found that caffeine ingestion above $300 \mathrm{mg} /$ day hastened spinal bone loss. Caffeine's diuretic effect causes the loss of both water and calcium and appears to be significant at consumption levels equivalent to two or more cups of coffee per day. This explanation was supported by the study conducted in the USA by Babatunde et al., (2011), found that the prevention intervention improved osteoporosis preventive behaviors by helping older individuals to increase their consumption of calcium-rich foods and to make informed choices about their diet quality and lifestyle.

The current study findings clarified also, the difference between pre-post intervention total level of knowledge scores were highly statistically significant $(\mathrm{P}=0.000)$. This indicates the success of the intervention in achieving these objectives of increase elderly knowledge and improves their quality of life by improving elderly practice exercise, take balanced diet contain calcium and prevent risk factors that lead to lack absorption of calcium. These results are in agreement with Nielsen et al, (2010) whose study done in Denmark showed that an educational program improved elders' knowledge, health beliefs, and intention to adhere to drug therapy, which is consistent with previous research on osteoporosis health behaviors.

Regarding adding salt on food the study revealed that no one continued adding salt after intervention this could be due to the patients' knowledge the effect of sodium on calcium excretion through the kidney. Sabin, \& Sarter (2014), agreed that there was a significant increase in salt intake (sodium and potassium) in their patients' sample. The high salt intake may cause osteoporosis because it increases calcium loss. Soda, pickles and excessive salt in your food hinder the absorption of calcium in the body. The finding goes in line with the study conducting in Korea by Lee \& Choi-Kwon, (2014), found that Dietary Approach to Stop Hypertension (DASH), which focuses on food high in calcium and potassium, was originally designed for regulation of high blood pressure had positive effects on bone mineral density.

On the same line, a study in England by Ward \& Prentice, (2011) found that a healthy balanced diet is required to maintain good bone health, as it is to maintain good general health. Bone requires a range of vitamins and minerals in order to remain healthy. The most important nutrients, vitamins and minerals required include calcium, vitamin $\mathrm{D}$, zinc, boron, copper, magnesium, vitamin $\mathrm{K}$, silicon and folic acid, among others.

The present study findings revealed that a high prevalence of lack of physical exercise with only about less than half of the elderly in studied sample practicing exercise before the intervention. However, it has been clarified that in our Egyptian culture we were not practicing any type of exercise even just walking. This related to the fact that we have no time or place or us is not interested in practicing exercise. This result stands in line with Etemadifar et al., (2013), in Iran emphasized that exercise has an important impact on bone health. Immobilization is an important cause of bone loss and should wherever possible be avoided. The amount of exercise that is optimal for skeletal health in patients with osteoporosis is not known, but regular weight-bearing exercise forms an integral component of management and should be tailored according to the needs and fitness of the elderly.

The present study showed improved in the quality of life of elderly suffered from osteoporosis by increased their knowledge about the disease. This was noticed in the areas of their knowledge about types of exercise lead to prevent osteoporosis which leads to improving the elderly quality of life post intervention implementation. These results are in agreement with Alqahtani (2014), whose study in Saudi Arabia demonstrated that an educational program could increase elderly's knowledge of osteoporosis \& produce lifestyle changes.

The present study revealed that there was highly statistically significant difference regarding exposure to the sun through educational intervention, this pertained to the patients knew the effect of the sun which is a source of vitamin D that helps in calcium absorption. The body also needs vitamin D to help in the process of absorbing calcium. The best source of this vitamin is the sun. In agreement with Tang et al., (2007), found that Vitamin D is formed by the action of sunlight on the skin and is important for calcium absorption from foods. The sun exposure that comes from normal daily activities is usually enough vitamin D needs.

On the same line Holick (2006), whose study in USA demonstrated that the main source of vitamin D comes from exposure of the skin to sunlight exposing the hands, face and arms to direct sunlight (without sunscreens or glass barrier) exposure of 5-15 minutes of sunlight 4-6 times a week outside the hours of 10 am and $2 \mathrm{pm}$ can prevent vitamin D deficiency. Hence, there is considerable seasonal variation in concentrations higher at the end of summer compared to other seasons. Recommended exposure of 5-15 minutes of sunlight 4-6 times a week outside the hours of 10 am-2 pm seems prudent.

Concerning nutritional behaviors, the current study results will be presented in two components first dietary intake which have positive effect on bone mineral density, it include; dairy products, legumes 
intake, vegetables fruits intake, intake protein $\&$ fish intake, balanced meals a day and calcium supplements, second risky dietary habits such as salt and pickles intake, soda, coffee, tea and smoking habits. In women, the peak bone mass is lower due to the hormonal changes that occur at menopause and the effect of pregnancy. Women need to be cautious about their diet and ensure that it is well balanced because failure to observe this, and given the hormonal changes, calcium composition in their bodies can be altered.

On the same respect, a study was done at Mauritian by Bhurosy \& Jeewon, (2013), who concluded that an educational intervention is effective in improving the dietary calcium intake, knowledge, and selfefficacy of older community adults. Similarly, Nakatani et al., (2012), they found that the implementation rates of health education on dietary calcium intake and exercise for elderly persons were higher in the intervention group. Specific advice on intakes of calcium and vitamin $\mathrm{D}$ and exercise became more evidence-based in the intervention group.

The current study findings revealed that before the intervention, all osteoporotic elders had a limitation in movement during daily live activity and emotional status. This could be attributed to osteoporosis negatively affects the patients' quality of life, limiting their performance in activities of daily living due to chronic pain generated by osteoporosis can lead to depression, anxiety, frustration and social isolation. In agreement with, El-Shazly \& Mahmoud, (2007) whose study conducted in Egypt found that the prevalence of osteoporosis among elderly is likely to be associated with the lower Ecos-16 score. Physical function, emotional status, and overall quality of life were significantly and negatively associated with osteoporosis. Moreover, elderly women with osteoporosis had a low quality of life such as chronic pain, reduce physical and emotional activity.

Regarding DEXA finding, the current study found that the improvements in bone mineral density are not significant; but significance improvement in cortical bone is found. This implies that insufficient knowledge linking to bone mineral status, growth rates or bone turnover in old age for these indices used as markers of osteoporotic disease risk. The early onset of low BMD among women complaining of bone aches strengthens the need for a routine checkup for BND during the childbearing period; this would provide a chance to identify high-risk individuals. This finding was supported by a study conducted in the USA by Resnick et al., (2014) whose study in the USA found that improving knowledge of osteoporosis and awareness of having a diagnosis of osteoporosis, decreasing fear of falling, and strengthening self-efficacy and outcome expectations for exercise may help improve bone mineral density among older adults. On the same line, Brecher et al., (2012) concluded that public health messages raise the awareness regarding the asymptomatic nature of osteoporosis, and provide greater clarity about the types of physical activity that target bone.

The possible explanation for this situation, osteoporosis was more common among elderly living in our country it may be due to living in worse socioeconomic conditions and had poorer literacy skills, less access to health care centers and accordingly less opportunity to acquire knowledge about osteoporosis from physicians.

This disagreed with Berkemeyer et al., (2009), who conducted a cross-sectional study (2005-2006) on community-dwelling elderly $(>=75$ years $)$ from Herne, Germany they measured bone T-score with Duel-energy x-ray Absorptiometry, and functional status indexed by five geriatric test: activities of daily living, instrumental activities of daily living, test of dementia, geriatric depression score and the timedup-and-go test. They found that osteoporosis associated with lower functional status in community dwelling elderly and they concluded that regular screening of osteoporosis as a preventive strategy might help maintain life quality with aging.

\section{Conclusion}

The results of the study were limited by the relatively small sample size. The current study findings clarified that, health education and apply onpharmacological intervention help elderly to modify their lifestyle in order to improve their bone health by improve elderly practice exercise, take balanced diet contain calcium and prevent risk factors that lead to lack absorption of calcium, slightly enhance activities of daily living for study subjects. There was a highly statically significant increase in the mean score of the knowledge and practice of the osteoporosis after the intervention compares to the level before implementation.

\section{Recommendations}

- Conversation and education about the risk factors and preventative measures of osteoporosis need to start early in the per menopausal years and not be delayed to the postmenopausal years as this may reduce morbidity later in life.

- Health education about nutritional behaviors and social activities will be helpful interventions to decrease the future incidence of osteoporosis. 


\section{References}

1. Alqahtani S., (2014): "A study of knowledge of women toward osteoporosis in primary care in King Abdulaziz military hospital in Tabuk", International Journal of Medical Science Public Health, Vol.3, No. 7, pp. 803-807.

2. Avenell, A., Gillespie, W., Gillespie, L., \& O'Connell, D., (2009): "Vitamin D and vitamin $\mathrm{D}$ analogs for preventing fractures associated with involutional and post-menopausal osteoporosis", Cochrane Database of Systematic Reviews, Vol. 2, CD000227.

3. Ayoub S., Nahed M., \& Soliman M., (2007): "Evaluation of the impact of the educational program on elderly knowledge about osteoporosis", Bulletin of High Institute of Public Health, Vol.2, pp. 399-414.

4. Babatunde O., Himburg S., Newman F., Campa A., \& Dixon Z., (2011): Theory-driven intervention improves calcium intake, osteoporosis knowledge, and self-efficacy in community-dwelling older black adults. Journal of Nutrition Education and Behavior, Vol. 43, No. 6, pp. 434-440.

5. Berecki-Gisolf, J., Spallek R., \& Dobson H., (2010): "Height Loss in Elderly Women is preceded by Osteoporosis and is associated with Digestive Problems and Urinary Incontinence", Osteoporosis Int., 21(3):Pp. 479-85.

6. Berkemeyer, S., Schumacher, J., \& Thiem, U., (2009): Bone T-Scores and functional status: Across-sectional study on German Elderly, Vol. 4, No. 12, Pp. 8216.

7. Bhurosy T., \& Jeewon R., (2013): "Effectiveness of a Theory-Driven Nutritional Education Program in Improving Calcium Intake among Older Mauritian Adults", Article ID 750128, 16 pages.

8. Body, J., Bergmann, P., Boonen, S., Boutsen, Y., Bruyere, O., Devogelaer, J., Goemaere, S., Hollevoet, N., Kaufman, J., Milisen, K., Rozenberg, S., \& Reginster, J., (2011): "Nonpharmacological of osteoporosis: a consensus of the Belgian Bone Club", Osteoporosis international, a journal established as result of cooperation between the European Foundation for Osteoporosis and the National Osteoporosis Foundation of the USA, Vol. 22, No. 11, pp.2769-2788.

9. Brecher L., Pomerantz S., Snyder B. A., Klotzbach D., Shimomura K., \& Caralieri T., (2012): "Osteoporosis prevention project: model multidisciplinary educational intervention, Journal of American Osteopath. Association; Vol.102, No.6, pp. 327-335.
10. Cauley, J., (2013): Public health impact of osteoporosis. Journal of gerontology, Series A, Biological sciences and medical sciences, Vol. 68, No. 10, pp. 1243-1251.

11. Centeral Intelligence Agency [CIA] (2014): the world fast book. "Field listing-age Structure", Available at website https://www.cia.gov/ library/publications.

12. Chan, S., Scott, B., \& Sen, S., (2010): “An Asian viewpoint on the use of vitamin D and calcium in osteoporosis treatment: Physician and patient attitudes and beliefs: BMC Musculoskeletal Disorders, Vol. 11, No. 9, pp. 248.

13. EL-Hajj Fuleihan G., Adib M., \& Nauroy L., (2011): "The middle east \& Africa regional audit; Epidemiology, costs \&burden of osteoporosis in 2011. Available at website: URL: http://www.iofbonehealth.org/download/osteofo und/filemanager/ publications/pdf/middle-eastadult-11/ME-adult.Pdf.

14. El-Shazly S., \& Mahmoud N., (2007): Measuring the Quality of Life among Elderly with Osteoporosis, quality of life of Osteoporotic Elderly, ASNJ. Vol. 6, No. 2, p. 23.

15. Englund, U., Nordstrom, P., \& Nilsson, J., (2011): " Physical activity in middle-aged women and hip fracture risk: the UFO study, Osteoporosis International, Vol. 22, No. 2, pp. 499-505.

16. Etemadifar M., Nourian S., FereidanEsfahani M., Shemshak H., Nourbakhsh M., \& Zarezadeh M., (2013): "Relationship of knowledge about osteoporosis with education level and life habits", World Journal of Orthopedic, Vol. 4, No.3, pp. 139-143.

17. Feldblum I., German L., Castel H., Harman-Boehm I., \& Shahar D., (2011): "Individualized nutritional intervention during and after hospitalization: the nutrition intervention study clinical trial', Journal of the American Geriatrics Society, Vol. 59, No. 1, pp. 10-17.

18. Fenton T., Eliasziw M., Lyon A., Tough S., \& Hanley D., (2008): "Meta-analysis of the quantity of calcium excretion associated with the net acid excretion of the modern diet under the acid-ash diet hypothesis". American Journal of Clinical Nutrition, Vol. 88, No. 4, pp. 1159-66.

19. Goltzman, D., (2008): "Largest ever Canadian study on osteoporosis informs health policy in Health \&Medicine", Available at website http://esciencenews.com.

20. Greco, E., Fornari, R., \& Rossi, F., (2010): "Is obesity protective for osteoporosis? Evaluation of bone mineral density in individuals with high 
body mass index", International Journal of Clinic Protection, Vol. 64, No. 6, pp. 817-820.

21. Gunary, E., Kisakol, G., \& Ozgen, G., (2003): "Effect of weight loss on bone metabolism: Comparison of vertical banded gastroplasty and medical intervention". Obstetric surgery, Vol. 13, pp. 383-388.

22. Gundi, S., Sitta, E., \& Fiunne, N., (2007): "Relationship between body composition and bone mineral density in women with and without osteoporosis: relative contribution of lean and fat mass, Journal of bone Mineral Metabolism, Vol. 25, pp. 326-332.

23. Hassan A., Abdel Galil B., \& Moussa D., (2012): "The double burden of malnutrition Case studies from six developing countries". Available at website http://www.fao.org.

24. Hassan, S., (2015): "A study of Morbidity Pattern among Geriatric Population in Fayoum Governorate, Egypt. Journal of American Science, 11 (4):90-95.". Available at website http://www.jofamericanscience.org.

25. Hernlund E., Svedbom A., Ivergård M., Compston J., Cooper C., Stenmark J., McCloskey E., Jönsson B., \& Kanis J., (2013): "Osteoporosis in the European Union: medical management", epidemiology and economic burden, Arch Osteoporos, Vol. 8, No. 1-2, pp. 136.

26. Holick M., (2006): "High prevalence of vitamin D inadequacy and implications for health", Mayo Clinic Proc; Vol. 81, No. 1, pp. 353-373.

27. Kanis, J., Johnell, O., Oden, A., Johansson, H., De laet, C., Eisman, J., Fihiwara, S., Kroger, H., McCloskey, E., Mellstrom, D., Melton, L., Pols, H., Reeve, J., Silman, A., \& Tenenhouse, A., (2005): "Smoking and fracture risk: a meta-analysis", Osteoporosis International, Vol. 16, No. 3, pp. 155-162.

28. Kim, K., Shin, D., \& Lee, S., (2010): "Relation between obesity and bone mineral density and vertebral fractures in Korean postmenopausal women, Yonsie of Medical Journal, Vol. 1;1115, No. 6, pp.857-863.

29. Korpelainen, R., Keinänen-Kiukaanniemi, S., and Heikkinen, J., (2006): "Effect of impact exercise on bone mineral density in elderly women with low BMD: a population-based randomized controlled 30-month intervention, Osteoporosis International, Vol. 17, No. 1, pp. 109-118.

30. Lee H., \& Choi-Kwon S., (2014): "Effects of a DASH diet-based Nutritional Intervention Program on Bone Health of Elderly Women", International Journal of Health Sciences, Vol. 2, No. 4, pp.81-98.
31. Lewiecki, E., (2011): "In the clinic. Osteoporosis", Annual International Medicine, Vol. 155, No. 1, pp.1-15.

32. Mac Laughlin J., \& Raehl L., (2008): "The American Society of Health-System Pharmacists [ASHP] Therapeutics position statement on the prevention and treatment of osteoporosis in Adults": American Journal Health-System Pharmacists, Vol. 65, No. 9, pp.343-357.

33. Nakatani Y., Tamaki J., Komatsu M., Iki M., \& Kajita E., (2012): "Effect of distributing an evidence-based guideline for prevention of osteoporosis on health education programs in municipal health centers: a randomized controlled trial", Journal of Epidemiology, Vol. 22, No. 2, pp. 103-12.

34. Nielsen D., Ryg J., Nielsen W., Knold B., Nissen D., \& Brixen K., (2010): "Patient Education and Counseling, Patient education in groups increases knowledge of osteoporosis and adherence to treatment": A two-year randomized controlled trial, Vol. 81, No. 2, pp. 155-160.

35. Prentice R., Pettinger M., \& Jackson R., (2012): "Health risks and benefits from calcium and vitamin D supplementation", Women's Health Initiative clinical trial and cohort study. Osteoporosis Int. Vol. 24, No. 2, pp. 567-580.

36. Radak, T., (2004): "Caloric restriction and calcium", the effect on bone metabolism and body composition in overweight and obese premenopausal women. Nutritional Review, Vol. 62, pp. 468-481.

37. Rariden T., (2012): "examination of the factors associated with osteoporosis among an elderly population in Genesee county, Michigan", Available at website http://w ww.umflint.edu.

38. Resnick B., Nahm E., Zhu S., Brown C., An M., Park B., \& Brown J., (2014): “The impact of osteoporosis, falls, fear of falling, and efficacy expectations on exercise among communitydwelling older adults", Orthopedic Nursing;Vol.33,No.5, pp. 277-286; quiz 287-8

39. Rizzoli R., Bianchi M., Garabedian M., McKay H., \& Moreno L., (2010): "Maximizing bone mineral mass gain during growth for the prevention of fractures in the adolescents and the elderly", Bone, Vol. 46, No. 2, pp. 294-305.

40. Sabin N., \& Sarter B., (2014): “Osteoporosis Prevention", Narrowing the Gap between Knowledge and application, a brief report. The Journal for Nurse Practitioners, Vol. 10, Issue 9.

41. Sweet, M., Sweet, J., \& Jeremiah, M., (2009): "diagnosis and treatment of osteoporosis. American Family Physician, Vol. 79, pp. 194200. 
42. Tang B., Eslick G., \& Nowson C., (2007): "Use of calcium or calcium in combination with vitamin D supplementation to prevent fractures and bone loss in people aged 50 years and older" a meta-analysis. The Lancet; Vol. 370, No. 9, pp. 657-666.

43. Veatergaard P., Rejnmark L., \& Mosekilde L., (2008): "Fracture risk associated with different types of oral corticosteroids and effect of termination of corticosteroids on the risk of fractures", Calcified Tissue, Vol. 82, No. 9, pp. 249-257.

44. Veatergaard P., Rejnmark L., \& Mosekilde L., (2009): "Hypertension is a risk factor for fractures", Calcified Tissue, Vol. 84, No. 11, pp. 103-111.

45. Ward K., \& Prentice A., (2011): "Evidence submission to APPOG: Inquiry into the role of nutrition in preventing osteoporosis and promoting good bone health. Nutrition \& Bone Health", MRC Human Nutrition Research, Cambridge. Vol. 96, pp. 53-58.

46. Wastta, N., Adler, R., Bilezikian, J., Drake M., Eastell, R., \& Orwoll, E., (2012): “Osteoporosis in men: an Endocrine Society clinic practice guideline. Journal of Endocrinal Metabolism, Vol. 9, No. 6, pp. 1802-1822.

47. Waugh E., Lam M., Hawker G., McGowan J., Papaioannou A., Cheung A., Hodsman A., Leslie W., Siminoski K., \& Jamal S., (2009): "Risk factors for low bone mass in healthy 40 60-year-old women: a systematic review of the literature". Osteoporosis international", a journal established as a result of cooperation between the European Foundation for Osteoporosis and the National Osteoporosis Foundation of the USA, Vol. 20, No. 1, pp. 1-21.

48. Wells, H., Wallence, L., \& Ballard, J., (2005): "comparison between 60 matched pairs of postmenopausal black and white women: analysis of risk factors related to bone mineral density. Maturities, Vol. 52 (3-4), pp. 356-363.

49. WHO, (2009): "BMI classification: Body mass index", from Wikipedia, the free encyclopedia available at www.enwikipedia.org/wiki/main page.

50. World Health Organization [WHO], (2014): Ageing and nutrition: a growing global challenge, Available at website http://www.who.int/nutrition/topics/ageing/en/. 